\title{
EL CONFESIONARIO REGIO EN LA MONARQUÍA HISPÁNICA DEL SIGLO XVII'
}

\author{
María Amparo López Arandia \\ Universidad de Córdoba
}

\begin{abstract}
RESUMEN. Durante la Edad Moderna, las elites eclesiásticas: obispos, capellanes, predicadores o confesores, especialmente cuando formaban parte de la corte o participaban en los principales órganos de la Administración -consejos, juntas, secretarías...- tendieron a ejercer una doble influencia no sólo como guias espirituales, sino como consejeros políticos. En este contexto, el objetivo de nuestro trabajo es prestar atención a la labor del confesor del rey en la Monarquía hispánica durante el siglo XVII, intentando ofrecer una primera aproximación en relación a su integración, influencia y actitud en diferentes instituciones de la Administración.

Palabras claves: Edad Moderna, siglo XVII, Monarquía hispánica, historia religiosa, confesor real.
\end{abstract}

AbSTRaCT. In the Early Modern period ecclesiastic elites: bishops, chaplains, priests or confessors, especially when they were around the court or they took part of the main institutions of the Administration -councils, committees, secretary ships...-, tended to become in a double way to impose their influence on the government, not only as spiritual guides, but also as political advisers. In this sense, the objective of our work is paying attention to the action of the royal confessor in the Hispanic Monarchy during the $17^{\text {th }}$ century. We shall try to

1 Trabajo enviado el 15/12/2009 y admitido para su publicación el 5/04/2010. El presente trabajo se ha realizado durante el disfrute de un contrato del programa Juan de la Cierva, en el Área de Historia Moderna de la Universidad de Córdoba. Igualmente, para su elaboración hemos contado con el apoyo de los proyectos de I+D+i HAR2008-04597 y HAR2008-01406, financiados por el Ministerio de Ciencia e Innovación; del proyecto de excelencia P07-HUM-02835 y del grupo de investigación HUM-155, financiados por la Junta de Andalucía; así como del proyecto de investigación UJA-07-16-27, financiado por la Universidad de Jaén. 
show a first approach about his participation, influence and attitude in relation to the different institutions of the Administration.

Keywords: Modern Age, $17^{\text {th }}$ century, Hispanic Monarchy, religious history, royal confessor.

"...un confessore del Re in Spagna è una cosa tanto grande, che quelche si fa per lui non uale la consiguenza che si habbia a far per altri, perche passando per sua consulta per lo meno tutte le cose ecclesiastiche et di conscienza, uiene ad abbracciar i piu principali negotii di tutta questa Monarchia, et ardirei di dire che in tutta Christianita difficilimente en sia oggi ministro piu considerabile..."2

En los últimos años, la sacralización del poder durante la Edad Moderna ha sido especial objeto de estudio para la historiografía francesa, italiana y española, por citar tres ejemplos. En este contexto, la corte, tema que también está siendo sometido a una revisión historiográfica, se presenta como un foco de atracción para numerosos religiosos que coparon los cargos de predicadores, capellanes o confesores, oficios que se convirtieron en una doble vía de influencia en el gobierno de la Monarquía, al permitir a sus poseedores actuar no sólo como rectores espirituales, sino como verdaderos consejeros políticos ${ }^{3}$.

Por otra parte, en una sociedad sacralizada como la de la Edad Moderna, el control de las conciencias adquiere una especial significación ${ }^{4}$, cuestión reafirmada aún más si cabe cuando atendemos al control de la conciencia del soberano. En este caso, el confesor no sólo actuaba como el responsable de la atención espiritual del monarca, sino que su posición le situaba, como bien ha señalado Jaime Contreras, en “...un lugar político de singular excepcionalidad...."

2 Archivo Secreto Vaticano (ASV), Borghese, serie II, 264, Nuncio en Madrid, 22 de septiembre de 1613 , fol. $220 \mathrm{r}$.

3 Para Rurale, de hecho, esta circunstancia debe remontarse al siglo XV, con precedentes como Dionigi il Certosino o Vicente Ferrer. RURALE, F.: "Il confessore e il governatore: Teologi e moralisti tra casi di coscienza e questioni politiche nella Milano del primo Seicento", en BRAMBILLA, E. e MUTO, G. (a cura di): La Lombardia spagnola. Nuovi indirizzi di ricerca, s. 1., Edizioni Unicopli, 1997, pp. 346347. Para el caso de los predicadores, NEGREDO DEL CERRO, F.: "La teologización de la política. Confesores, valido y gobierno de la Monarquía en tiempos de Calderón", en ALCALÁ-ZAMORA, J., BELENGUER, E. (Coords.): Calderón de la Barca y la España del Barroco, Madrid, Centro de Estudios Políticos y Constitucionales, Sociedad Estatal España Nuevo Milenio, 2001, pp. 707-724; NEGREDO DEL CERRO, F.: Política e Iglesia: Los predicadores de Felipe IV, Tesis digitales, Madrid, Universidad Complutense, 2001, pp. 13, 66, NEGREDO DEL CERRO, F.: Los predicadores de Felipe IV. Corte, intrigas y religión en la España del Siglo de Oro, Madrid, Actas, 2006.

4 Véase, como especialmente ilustrativos, DELUMEAU, J.: L'Aveu et le pardon: les difficultés de la confession, XIIIe-XVIIIe siècle, París, Fayard, 1990; y PROSPERI, A.: Tribunali della coscienza. Inquisitori, confessori, missionari, Torino, Einaudi, 1996 (Nuova edizione, 2009).

5 CONTRERAS CONTRERAS, J.: ““'Descargar” la conciencia real: ¿confesor o ministerio?”, en ALVAR, A., CONTRERAS, J. RUIZ, J. I. (Eds.): Politica y cultura en la época moderna. (Cambios 
Esta percepción se encuentra relacionada con el propio concepto de soberanía, que situaba al rey como delegado directo de Dios, y por tanto, a su confesor en el único individuo que podía "pedirle cuentas" de su actuación. De hecho, las atribuciones del confesor, el médico del alma, como es definido en numerosos tratados de la época, adquieren unas especiales connotaciones cuando se trata del confesor del rey. Éste era responsable de la atención espiritual del hombre, como tal, pero al mismo tiempo de la del soberano. ¿Y cómo separar ambos conceptos? Un dilema latente en el siglo XVII, que pretende ser justificado por numerosos coetáneos, desde el padre Rivadeneira $^{6}$ a Jean Suffren, confesor de Luis XIII ${ }^{7}$.

La aparente incapacidad para discernir dónde terminaban los pecados del monarca como hombre y dónde empezaban los del soberano, responsable de toda una comunidad, implicó que el confesor real comenzara a adquirir, desde el reinado de Isabel la Católica, como ha apuntado Iannuzzi ${ }^{8}$, unas cada vez mayores cotas de poder en el ámbito político, en las que las funciones como consejero ocuparon un lugar de enorme peso, trascendiendo, por tanto, de su mera misión como hombre de Iglesia.

Aunque el confesor no era el único religioso influyente en la corte, éste se encontraba en la cúspide, junto al monarca, teniendo acceso directo a él, cuestión de enorme significación en un mundo cortesano marcado por la rigidez de las etiquetas y el ceremonial que restringían en gran medida la proximidad al soberano.

A pesar de que no existió una estricta norma dictada por la etiqueta de las casas de Borgoña, de Castilla ni Aragón, el confesionario regio en la Monarquía hispánica, por tradición, estuvo ocupado habitualmente por miembros de la orden de Predicadores desde el reinado de Enrique II hasta Carlos II, aunque en el siglo XVI en

dinásticos. Milenarismos, mesianismos y utopías), Alcalá de Henares, Universidad de Alcalá-Fundación Española de Historia Moderna, 2004, p. 492. Contreras, en este mismo trabajo, llega a ser aún más explítico, al considerar el cargo de confesor real como un "elevado ministerio político". CONTRERAS CONTRERAS, J.: "Descargar...", p. 494.

6 Para el caso de la Monarquía hispánica, véase, CASTELLANO CASTELLANO, J. L.: "La Monarquia spagnola come paradigma di una monarchia confessionale", en Dimensioni e problemi della ricerca storica, 1, 2008.

7 “...Le prince a des péchés d'homme et des péchés de roi. Il ne suffit donc pas de l'absoudre uniquement de ce qu'il a fait comme homme (...) On est confesseur non de Louis de Bourbon, mais de Louis XIII. Donc le confesseur est à la cour pour remédier aux péchés qui naissent aussi bien de la pourpre royale que du mortier d'Adam. Et comment concevoir qu'il soit donné au roi pour l'absoudre seulement des péchés d'homme et non pas de ceux de roi?...". Recogido por MINOIS, G.: Le confesseur du roi. Les directeurs de conscience sous la monarchie française, París, Fayard, 1988.

8 IANNUZZI, I.: "La conciencia de una Reina: Isabel I de Castilla", en LÓPEZ-CORDÓN, Ma. V., FRANCO RUBIO, G. (Coords.): La Reina Isabel I y las Reinas de España: Realidad, modelos e imagen historiográfica, Madrid, Fundación Española de Historia Moderna, 2005, pp. 138-140. Igualmente, puede resultar interesante, IANNUZZI, I.: "Gobernar a los fieles y "predicar" discursos socio-religiosos. Fray Hernando de Talavera, confesor y consejero de los Reyes Católicos”, en Entre el cielo y la tierra Las elites eclesiásticas en la Europa Moderna. Revista Universitaria Mágina, 13, 2009, pp. 73-84. 
determinados momentos se contó con religiosos de otras órdenes para cumplir dicha tarea, siendo posible localizar en él a integrantes de la orden franciscana-Francisco de Cisneros, con Isabel la Católica y Diego de Fresneda, con Felipe II- o jerónima -Hernando de Talavera, también con Isabel, o Juan de Regla, con Carlos V-.

Esta preeminencia de la orden dominica en el confesionario hasta la llegada de Felipe V marca una diferencia con otras casas reales europeas, donde la Compañía de Jesús accede al cuidado de la conciencia real desde la segunda mitad del siglo XVI: en Portugal desde el reinado de Juan III, en una decisión en la que incluso se involucró el propio Ignacio de Loyola ${ }^{9}$; en Polonia, desde el reinado de Esteban Báthory ${ }^{10}$, en Francia, desde que en 1583, Émond Auger se erigiese como confesor de Enrique III ${ }^{11}$; así como a inicios del siglo XVII, controlando los confesionarios de los emperadores Fernando II ${ }^{12}$ y Leopoldo I, o el de Maximiliano de Baviera ${ }^{13}$.

\section{Un monopolio dominico}

\section{a) Una isla entre confesores regios jesuitas}

La orden de los Predicadores, en la Edad Media rectora del confesionario real en cortes como Francia o Inglaterra, ejercía a inicios del siglo XVII únicamente su do-

9 Sobre la presencia de los jesuitas en el confesionario regio de Portugal, MARQUES, J. F.: "Os jesuítas, confessores da corte portuguesa na época barroca (1550-1700)", en Revista da Faculdade de Letras. Historia, 12, 1995, pp. 231-270; MARQUES, J. F.: "Confesseurs des princes, les jésuites à la Cour de Portugal", en GIARD, L. et VAUCELLES, L. de: Les jésuites à l'âge baroque 1540-1640, Grenoble, Jèrome Millon, 1996, pp. 213-228; RODRIGUES, F.: Histórica da Companhia de Jesus na assistência de Portugal, Porto, Apostolado da Imprensa, 1931-1944, tomo I/2, pp. 18-23; tomo III/1, pp. 503-539 y tomo IV/1, pp. 425-428 y 446-454.

10 OBIREK, S.: Jezuici na dworach Batorego i Wazów (1580-1668), Kraków, WFTJ, 1996.

11 Para la labor de los confesores regios de la Compañía, vid. MINOIS, G.: Le confesseur.... Para la actuación concreta de alguno de estos personajes, GUITTON, G.: Le Père de la Chaize, confesseur de Louis XIV, París, Beauchesne et ses fils, 1959, 2 vols.; LYNN MARTIN, A.: Henry III and the Jesuit politicians, Genève, Droz, 1973; PRAT, J. M.: Recherches historiques et critiques sur la Compagnie de Jésus en France du temps du P. Coton, Chez Lyon, Briday, Libraire-éditeur, 1876-1878, vols. 3 y 4; ROCHEMONTEIX, C. de: Nicolas Caussin, confesseur de Louis XIII, et le Cardinal de Richelieu, París, A. Picard et fils, 1911.

12 Sobre la presencia de la Compañía de Jesús en el confesionario imperial, BIRELEY, R.: Religion and politics in the age of the Counterreformation. Emperor Ferdinand II, William Lamormaini, S. J., and the formation of imperial policy, Chapel Hill, The University of North Carolina Press, 1981.

13 En relación a la presencia de la Compañía en el confesionario de la casa de los Neoburgo, véase, LÓPEZ ARANDIA, Ma . A.: "El poder de la conciencia. Fr. Gabriel de Chiusa, confesor de Mariana de Neoburgo", en MARTÍNEZ MILLÁN, J. (Ed.): La dinastía de los Austria: las relaciones entre la Monarquía Católica y el Imperio, Madrid, Polifemo, (en prensa); y LOZANO NAVARRO, J. J.: "Una aproximación a la relación entre el poder político y la Compañía de Jesús: la Casa de Neoburgo y los jesuitas (siglos XVI-XVIII)", en CORTÉS PEÑA, A. L., BETRÁN, J. L. y SERRANO MARTÍN, E. (Eds.): Religión y poder en la Edad Moderna, Granada, Universidad de Granada, 2005, pp. 53-65. 
minio sobre el confesionario regio de la Monarquía hispánica. Una centuria en la que, a pesar del paulatino ascenso de la Compañía de Jesús a los confesionarios de los círculos cortesanos de mayor influencia - recordemos los del conde-duque de Olivares, pero incluso los de las reinas Margarita de Austria $^{14}$ o Mariana de Austria ${ }^{15}$ - , la orden ignaciana no consiguió hacerse con el control de la conciencia del soberano.

El auge de la acción de la Compañía vino acompañado de una verdadera ola de escritos que recelaban de su labor, y especialmente de lo que para muchos representaba un denodado interés por ejercer un poder temporal, para el que el control de las conciencias - ante todo, de la de los individuos con mayor poder - se convertía en una pieza clave. Recordemos las quejas del arzobispo de Dublín a este respecto, u obras como Plaidoyes des curés de Paris, editada en 1594, incluso las palabras que Clemente VIII pronunciaba en la congregración de Roma de 1594, reprochando, entre otras cosas, la actitud jesuita en el confesionario ${ }^{16}$.

La propia Compañía no fue ajena a esta situación. Muestra de ello son las Istruzioni dei principi, redactadas por el general Aquaviva en 1602, uno de los numerosos documentos relativos al gobierno de la orden que impulsó durante su generalato. En dicho documento, el general intentó regular el comportamiento y actuación de los confesores jesuitas, recomendándoles no inmiscuirse en asuntos políticos; exigiendo se mantuvieran ajenos a intrigas palaciegas, que guardasen el secreto de confesión no informando a otros personajes de la corte de los asuntos tratados con los monarcas y evitando dar mensajes en nombre del príncipe, en definitiva, “...ricordi di esser solo confessore, $e$ che tutte le cose che sono aliene di questo officio devono esser aliena da lui... "'17.

14 SÁNCHEZ, M., "Confession and complicity: Margarita de Austria, Richard Haller, S.J., and the court of Philip III", en Cuadernos de Historia Moderna, 14, 1993, pp. 133-149.

15 En relación a Nithard, LOZANO NAVARRO, J. J.: La Compañía de Jesús y el poder en la España de los Austrias, Madrid, Cátedra, 2005, pp. 297-335; LOZANO NAVARRO, J. J.: "Los inicios de la regencia de Mariana de Austria y el ascenso del padre Nithard al poder desde el punto de vista de la Compañía de Jesús", en MOLINIÉ, A., MERLE, A. et GUILLAUME-ALONSO, A. (Dirs.): Les jésuites en Espagne et en Amérique, París, PUPS, 2007, pp. 63-82; LOZANO NAVARRO, J. J.: "La embajada controvertida: el padre Nithard en Roma (1670-1681)", en VISCEGLIA, Ma. A. (a cura di): Diplomazia e politica della Spagna a Roma: figure di ambasciatori. Roma moderna e contemporanea, 1-3, 2007, pp. 271-291; PINEDO, I y PLATGUMMER, H.: "NITHARD (NITHARD), Johann Eberhard", en O'NEILL, Ch. E., DOMÍNGUEZ, J. Mª. (Dirs.): Diccionario histórico de la Compañia de Jesús. Biográfico-temático, Roma-Madrid, Institutumm Historicum S. I.-Universidad Pontificia de Comillas, 2001, vol. III, pp. 2818-2819.

16 “...quieren saber en todo y saberlo todo en el confesionario y queriendo saber del penitente, de lo que passa en su casa, de sus hijas y criados y de la demás gente, si confiessan a un príncipe, no de aver negocio que no passe por sus manos hasta el estado lo quieren gobernar y dar a entender que no faltará nada sin su industria y diligencia...". Recogido por GARCÍA CÁRCEL, R.: "La crisis de la Compañía de Jesús en los últimos años del reinado de Felipe II (1585-1598)", en RIBOT GARCÍA, L. (Coor.): La monarquía de Felipe II a debate, Madrid, Sociedad Estatal para la conmemoración de los centenarios de Felipe II y Carlos V, 2000, p. 398.

17 Las instrucciones, conservadas en el Archivum Romanum Societatis Iesu, son reproducidas en parte por RURALE, F.: "Il confessore e il governatore: Teologi e moralisti tra casi di coscienza e questioni politiche nella Milano del primo Seicento", en BRAMBILLA, E. e MUTO, G. (a cura di): La Lombardia 
A inicios del siglo XVII, el propio Felipe III aún se mantenía oficialmente reacio a que la Compañía de Jesús copase los confesionarios de individuos influyentes en la Monarquía, como consta por la carta remitida el 1 de marzo de 1603 al duque de Sessa, embajador en Roma, obligando que fuese el propio general el que señalara a las personas más adecuadas para dicho fin ${ }^{18}$.

Paralelamente, en estos años se difundió con gran profusión en la Monarquía hispánica, como en buena parte de Europa, la Monita secreta, texto antijesuítico del siglo XVII por excelencia, aparecido por primera vez en 1612, que dedicaba todo un capítulo de los diecisiete que componían la obra, el segundo, a atender a la estrecha vinculación de la orden ignaciana con los príncipes y soberanos. El texto, redactado a modo de instrucciones secretas que habrían de cumplir los miembros de la orden religiosa, constituía en realidad un ataque encubierto a la Compañía. Al intentar presentar la relación entre la orden y los monarcas se incide en la cuestión del interés particular de la orden ignaciana, y de cómo el confesionario y el púlpito en las cortes europeas sería empleado como vía para promocionar a los partidarios a su causa.

De hecho, aunque a lo largo de la centuria los jesuitas consolidaron su presencia en la corte mediante diversas vías, sobre todo, como hemos señalado, a través del acceso a confesionarios como el del conde duque o el de Margarita de Austria, Mariana de Austria o en un primer momento, el de Mariana de Neoburgo, y a pesar de las altas cotas de poder que consiguió Nithard, incumpliendo la voluntad recogida en el testamento del propio Felipe IV, la conciencia del heredero se mantuvo en manos de los dominicos durante toda la centuria.

\section{b) El fallido proyecto del control de la conciencia regia}

El control del confesionario por parte de los dominicos tampoco estuvo exento de críticas, algunas tan voraces como las dedicadas por Quevedo en su Política de

spagnola. Nuovi indirizzi di ricerca. S. 1., Edizioni Unicopli, 1997, pp. 362-363. Un detallado análisis de las mismas, también, en MINOIS, G.: Le confesseur..., pp. 334-339.

18 Archivo General de Simancas (AGS), Estado, Roma, 978. Recogido por DOMÍNGUEZ ORTIZ, A.: La sociedad española en el siglo XVII, vol. II.- El estamento eclesiástico, Edición facsímil. Granada, Universidad de Granada, 1992, p. 253. Unos días antes, a la nunciatura habían llegado noticias sobre la decisión del monarca. OLARRA GARMENDIA, J. de; LARRAMENDI, M ${ }^{a}$. L.: Correspondencia entre la Nunciatura de España y la Santa Sede en el Reinado de Felipe III (1598-1621), Roma, Iglesia Nacional Española, 1962, tomo II, Nuncio Ginnasio al cardenal Pedro Aldobrandini, Valladolid, 22 de febrero de 1603 , pp. 120-121. 
Dios, gobierno de Cristo nuestro señor ${ }^{19}$ o en Grandes Anales para quince días ${ }^{20}$. Críticas en las que el abuso de poder o la injerencia en asuntos políticos también salieron a la luz. Una preocupación que advertimos desde inicios del siglo XVII.

Un punto interesante en este contexto es atender al intento, por Juan de Ribera, arzobispo de Valencia, de proponer la creación de un consejo de Conciencia que regulara y limitara las atribuciones del confesor real. Una institución que ya contaba con un precedente en Portugal y que décadas más tarde se implantaría en Francia tras la muerte de Luis XIII' ${ }^{21}$.

Juan de Ribera presentaba un memorial, cuyo original de 1608 se conserva en la Biblioteca Bartolomé March, en Mallorca, y del que poseemos una copia datada en 1610 custodiada en la Biblioteca Nacional de Madrid, el cual representa una abierta crítica a las atribuciones extra-espirituales que habían recaido en el confesor regio ${ }^{22}$, partiendo de un caso concreto, el de fray Gaspar de Córdoba, confesor entre 1597 y $1604^{23}$. Ribera, claramente contrario con la dedicación del confesor en actividades alejadas de los aspectos espirituales, reclamaba su alejamiento de comisiones, juntas y del consejo de Estado:

19 Entre los duros ataques de Quevedo localizamos alusiones como “(...) Ministros, allegados y confesores que son caminos sin verdad, son despeñaderos y sendas de laberinto que se continúan sin diferencia, en ceguedad y confusión: en estos tales ve Dios librada la perdición de los reyes y el açote de las monarquías. Espíritu de mentira en la boca del consejero, ruina del rey y del reino (...)”.' QUEVEDO VILLEGAS, F. de: "Política de Dios, gobierno de Cristo nuestro Señor", primera parte, cap. XXII, en QUEVEDO VILLEGAS, F. de: Obras completas, Madrid, M. Aguilar, 1932, p. 348.

20 RONCERO LÓPEZ, V.: Los Grandes Anales de Quince Días de Quevedo, Madrid, Ed. Complutense, 1988, ante todo, pp. 277-278.

21 Al respecto, MOUSNIER, R.: Les institutions de la France sous la monarchie absolute 15981789, París, Presses Universitaires de France, 1994, ante todo, vol. 1, p. 253-268; y vol. 2, pp. 157-158.

22 Diversas notas sobre el memorial de Ribera conservado en los fondos de la Biblioteca Bartolomé March (signatura 23/11/1/I) en GARCÍA Y GARCÍA, B. J.: "El confesor fray Luis de Aliaga y la conciencia del rey", en RURALE, F. (a cura di): I religiosi a corte: teologia, politica e diplomazia in Antico Regime, Milano, Bulzoni, 1998, pp. 159-194; y POUTRIN, I.: "L'oeil et le souverain: Luis de Aliaga et le métier de confesseur royal sous Philippe III", en SCHOLZ, J.-M. et HERZOG, T. (Dirs.): Observation and Communication: The construction of realities in the Hispanic World, Frankfurt am Main, Vittorio Klostermann, 1997, pp. 253-270, en especial, pp. 258-270.

23 Hijo del conde de Priego, don Martín Fernández de Córdoba y de doña María Lasso de la Vega. Fue designado confesor del aún príncipe Felipe (futuro Felipe III), en 9 de julio de 1597. Por entonces, ya era un destacado miembro de su orden, puesto que en el instante de su nombramiento ostentaba el cargo de provincial de la provincia Bética. Atendió el confesionario regio hasta su fallecimiento en Valladolid, acaecido el 14 de enero de 1604. Archivo General de Palacio. Madrid (AGPM), Personal, expediente personal, caja 550, exp. 1 (el expediente corresponde a Fr. Francisco Lillo). Una semblanza del personaje en LÓPEZ ARANDIA, M". A.: "Médicos del alma regia. Confesores reales en la España de los Austrias (siglo XVII)", en FERNÁNDEZ GARCÍA, J. y BEL BRAVO, Ma. A. (Eds.). Homenaje de la Universidad a don José Melgares. Jaén, Universidad de Jaén-Centro Asociado UNED “Andrés de Vandelvira”, 2008. 
...Vuestra Magestad no mande emplearlos en comissiones, ni juntas, y menos en offiçio de consejero de Estado, porque el confessor ha menester saber, y para saber no basta aver estudiado, pero es menester aver estudiado, y estudiar; y así quando llegan a ser confessores eran doctos, y en poco tiempo lo dexan de ser, ocupados en negocios de cuentas y de Estado, a lo qual todos vienen nuevos, y así es menester que lo aprendan, y como de contar reales a contar millones, y governar un convento de frayles a governar el mundo, hay tan grande distançia, se puede con razon temer, que por su edad y ocupaçiones aprendan tarde lo que no sabían, y olviden luego lo que avían estudiado, de que también necessariamente ha de resultar facilidad de engaños, de manera que faltando a su ministerio, faltan también al servicio de Vuestra Magestad...24.

En este sentido, criticaba la dedicación del confesor regio en actividades alejadas de aspectos más ligados a la espiritualidad como “...estudiar y encomendarse a Nuestro Señor y tratar con personas zelosas de la honra de Dios... ”25, invirtiéndolo en audiencias en la corte.

Aunque ante todo, para el arzobispo de Valencia, había que hacer frente a los deseos personales de los confesores reales por utilizar su cargo como recurso para alcanzar dignidades episcopales ${ }^{26}$.

El medio para regular las funciones del confesor, en su opinión, sería la creación de un nuevo consejo que atendería la conciencia regia, y que estaría integrado por tres individuos: el propio confesor real y dos renombrados teólogos que habrían de proceder de las universidades de Salamanca, Valladolid o Alcalá. Entre sus misiones se encontrarían la de atender a las consultas y pareceres que fuesen remitidos por los consejos o consejeros; serían los responsables de realizar "listas de personas exemplares y doctas" que podrían ocupar las plazas eclesiásticas vacantes; formar parte de las posibles juntas de teólogos o tratar aspectos relativos tanto a la conciencia regia, como a la moral pública, lo que les supondría ejercer, igualmente, el control sobre la oratoria sagrada crítica con el gobierno de la Monarquía, adquiriendo, por tanto, al mismo tiempo, un papel de censores ${ }^{27}$. Esta delegación de poderes supondría que el confesor tendría únicamente como responsabilidad exclusiva la atención espiritual al monarca.

24 Biblioteca Nacional. España (BNE), Ms. 5758, fol. 1 vo.

25 Ibídem.

26 Ibídem.

27 Ibídem, fol. 1 ro . En este sentido, dejaba claro cómo no sería su misión atender a todos los asuntos, sino simplemente en aquellas ocasiones en que los consejos o consejeros demandasen su parecer, al señalar expresamente que en ningún caso su misión debía ser “...corregir lo que los dichos consejos ordenasen pues en todos tiene V. M. personas de conciencia...". 
Con el fin de fundamentar su propuesta, que según él mismo señalaba había sido planteada a otros tres confesores que no habían considerado oportuno remitírsela al soberano, aludía directamente a la Mesa de Cosciencia portuguesa, institución, a su entender que "...sabemos sale bien y se consiguen en ella efectos de mucho seruicio de nuestro Señor y V. M. y consuelo de sus vasallos..."28.

Fray Luis de Aliaga fue el encargado de responder al memorial presentado por Ribera al llegar confesionario de Felipe III en diciembre de $1608^{29}$. Éste no tardó en rechazar la propuesta. El primer inconveniente, en opinión del nuevo confesor, era el hecho de que en el soberano recaían dos personalidades: la del hombre particular y la del rey ${ }^{30}$. Dicha circunstancia revalorizaba especialmente la figura del confesionario regio, convirtiéndolo, a entender de Aliaga, en la principal institución de la Monarquía: “...El tribunal interno de la conciencia es superior a todos los tribunales reales, quanto es maior la nobleza del alma, a quien el confesor juzga, que todos los negocios temporales, que los otros presidentes en sus consejos tratan (...) es el tribunal visible de Dios en la tierra..." 31.

Al mismo tiempo, defendía la integridad de sus antecesores, negando el deseo de éstos por acaparar dignidades episcopales, como había indicado el arzobispo valenciano, responsabilizando únicamente al monarca de su promoción; rechazaba las afirmaciones de Ribera sobre el excesivo tiempo empleado en audiencias sobre cuestiones ajenas a la religión, justificando, además, su presencia en las juntas ${ }^{32}$.

Obviamente, Aliaga negaba la necesidad de crear un consejo de Conciencia, alegando la necesidad de que el monarca contase con un número de ministros limitado, ante todo en aspectos referentes a la conciencia, con el fin, según él, de garantizar

28 Ibídem, fol. $2 \mathrm{r}^{\circ}$.

29 Sucesor de fray Jerónimo Xavierre en el confesionario real, de quien fue su protegido. Nació en Zaragoza en 1565, en el seno de una familia de comerciantes de paños. No era un desconocido en la corte, a la que había llegado sirviendo a Xavierre. Poco después había accedido al puesto de confesor del duque de Lerma. Recibió el título de confesor de Felipe III en 6 de diciembre de 1608, nombramiento ratificado en 10 de abril de 1609. Desde enero de 1619, compatibilizó dicha actividad con la de inquisidor general hasta 1621. La muerte de Felipe III y la caída del duque de Uceda, a quien se encontraba muy próximo, marcaron su salida de la corte, decretada por Felipe IV el 23 de abril de 1621, ordenando su destierro al convento dominico de Huete, desde donde pasó a Zaragoza. Allí, retirado en su ciudad natal, falleció el 13 de diciembre de 1626. AGPM, Personal, expediente personal, caja 45. Una semblanza más amplia del personaje, en LÓPEZ ARANDIA, Ma . A.: "Médicos del alma...".

30 BNE, Ms. 5758, fol. 6 v : “...Es obligacion del confesor, a quien puso Dios por centinela de la conciencia del Rey y fiscal de todos los presidentes y consejos, proponer a S. M. los exemplos de la Sagrada Escritura y doctrina de los santos padres, para que el sancto temor de Dios le obligue a mantener en justicia a sus vasallos...". Suffren.

No resulta exclusivo de Aliaga este planteamiento, recordemos las palabras ya citadas de

31 Ibídem, fol. 8 ro.

32 Ibídem. 
el secreto y de evitar la aparición de $\operatorname{conflictos}^{33}$, señalando que todo debía reducirse a una buena elección de la persona que se encargase del confesionario: “...docto, verdadero, desinteresado, bien intencionado, capaz de confiança y tal que no se ensoberbezca con ella, ni use mal della y a de ser tan a satisfacion de V. Magestad que no la teniendo es bien mude Vuestra Magestad de confesor, aunque sea mañana..."34.

\section{c) El ocaso del XVII. La defensa del confesionario}

Una nueva circunstancia que nos denota la significación que para cualquier orden religiosa representaba el control de la conciencia del soberano la localizamos en pleno reinado de Carlos II $^{35}$.

En estos instantes la llegada de Nithard al gobierno, el desembarco de jesuitas en los confesionarios de numerosos cortesanos, las discrepancias entre órdenes religiosas, ante todo de dominicos y jesuitas, especialmente patentes en la capilla real, amenazaban la hegemonía de la orden dominica, como custodia de la conciencia del rey.

Un claro ejemplo de esta cuestión lo constituye el cruce de críticas impresas a favor y en contra de estas órdenes que se difundieron por Madrid de forma anónima. Impresos como la Copia de lo que cierto prebendado en la corte escrivio a vn religioso de Santo Domingo, maestro suyo, en el que se clamaba al rey el alejamiento de la orden dominica del confesionario ${ }^{36}$, respondido en la Copia de lo que un doctor de cierta Vniversidad de España escriuio a vn prebendado en la Corte, donde se acusaba directamente a la Compañía de encontrarse detrás de los ataques, con la única pretensión de alcanzar el confesionario del rey, son una mera muestra de ello ${ }^{37}$.

Una defensa que tuvo, sin duda, su etapa más notoria durante el gobierno de fray Pedro Álvarez de Montenegro (confesor de Carlos II entre 1668-1675 y 1677-1678)²,

33 “...Al dictamen del pontifice es quien solo debe rendirse el confessor del principe, no al de otros theologos, que miran a su combeniencia, y assi en algun caso muy difficultoso consulte la Santa Sede V. S. I. y obrando según lo que declara el oraculo visible de la Iglesia estara segura su consciencia, ni tendra cosa que le pueda calumniar el Rey, ni los vasallos...”. Ibídem, fol. 19 ro.

34 Ibídem, fol. $26 \mathrm{r}^{\mathrm{o}}$.

35 Para esta cuestión, véanse nuestros trabajos "Un criado muy antiguo de la real casa. La orden dominica en el confesionario de Carlos II", en Entre el cielo y la tierra. Número monográfico revista universitaria Mágina, 13, 2009, pp. 113-158 y "El sacrílego tirano de la conciencia del monarca. Fray Pedro Matilla, confesor de Carlos II (1686-1698)", en CASTILLO GÓMEZ, A. y AMELANG, J. (Dirs.): La ciudad de las palabras. Opinión pública y espacio urbano en la Edad Moderna, Oviedo, Trea, 2010 (en prensa).

36 BNE, VE/211-78

37 BNE, VE/186-26, Copia de lo que vn doctor de cierta Vniversidad de España escriuio a vn prebendado en la Corte.

38 Natural de Valladolid, fue confesor de Carlos II durante la regencia, entre el 27 de noviembre de 1668 y noviembre de 1675. Durante esta primera etapa al frente del cargo y ante los cambios políticos, pasó de sus inclinaciones hacia Nithard a aproximarse a don Juan José de Austria, posición que implicó su 
quien articuló la puesta en marcha de una estrategia de férrea defensa de la posición de su orden en el confesionario, arguyendo a la tradición de las casas de Aragón y Castilla como principal argumentación para justificar su mantenimiento en el cuidado de la conciencia del monarca, para lo que llegó incluso a encargar la realización de una obra a Diego José Dormer sobre los confesores reales de la casa de Aragón ${ }^{39}$.

A partir de la década de los setenta apreciamos, de hecho, un intento desesperado de la orden de Predicadores por justificar - y mantener — su hegemonía en dicho oficio, en unos años en que no sólo resultaba patente la inestabilidad del confesionario regio, convertido en un instrumento más de las luchas entre facciones en la corte, sino situado en el punto de mira de las distintas potencias europeas ante el problema sucesorio que parecía avecinarse. Así, conocemos un documento, redactado en torno a la década de los ochenta, intitulado Nomina o relación de los confesores de los Reyes y Pontifices de la Orden de Predicadores, en el que remontándose de nuevo a la Edad Media, se presentaba la nómina de los dominicos que habían atendido la conciencia de monarcas, familias reales y pontífices en Europa ${ }^{40}$; o un escrito anónimo, datado tan sólo un mes después del fallecimiento de Carlos II, donde se llegaba, incluso, a falsear un supuesto desempeño del oficio de confesor del rey por los dominicos, de forma ininterrumpida ${ }^{41}$, intentando establecer una diferenciación entre los que se califican como "confesores de Estado", de los que denominan "confesores interinos", términos que permitían agrupar como los primeros a los de su orden, frente a otros individuos que en determinados momentos habían roto, en realidad, esa hegemonía, omitiendo, por otra parte, y muy probablemente de forma interesada, el desempeño de la labor de confesor del rey, con las funciones que se atribuyen a los denominados “confesores de Estado" por parte de personajes como el franciscano fray Bernardo de Fresneda, confesor de Felipe II $^{42}$.

directo cese cuando el hermanastro del rey fue cesado. Fue designado familiar del Santo Oficio de Valladolid en 1677. En este mismo año, tras un tiempo alejado del confesionario, fue restituido en su cargo en 8 de febrero, después del regreso de don Juan José de Austria, sustituyendo a fray Gabriel Ramírez de Arellano, hasta el 15 de junio de 1678, cuando "entre la vna y dos de la mañana" falleció en el convento de Nuestra Señora del Rosario, de Madrid, donde residía. A.G.P.M. Personal, exp. personal, caja 1337, exp. 6. Una semblanza del personaje en LÓPEZ ARANDIA, Ma . A.: "Médicos del alma...".

39 BNE, Mss. 12016, “De los confesores o Padres de Conciencia de los Señores Reyes de Aragón”, fols. $42 \mathrm{r}^{\mathrm{o}}-48 \mathrm{v}^{\mathrm{o}}$.

40 Archivo Histórico Nacional (AHN), Nobleza, Fernán Núñez, C. 20, D. 61. El documento no se encuentra datado, aunque a tenor de las informaciones recogidas en él parece haberse redactado en tiempos de fray Pedro Matilla, confesor de Carlos II entre 1686 y 1698.

41 BNE, VE/31/64. Una copia impresa del mismo en BNE, Mss. 5758, fols. 43 r-48 v.

42 PIZARRO LLORENTE, H., "El control de la conciencia regia. El confesor real fray Bernardo de Fresneda”, en MARTíNEZ MILLÁN, J. (Dir.): La corte de Felipe II. Madrid, Alianza Editorial, 1994, pp. 149-188; TELLECHEA IDÍGORAS, J. I., "Pole, Carranza y Fresneda. Cara y cruz de una amistad y de una enemistad", en TELLECHEA IDÍGORAS, J. I.: El arzobispo Carranza. "Tiempos recios", tomo 


\section{El confesor en el gobierno de la Monarquía Hispánica}

La pugna de la Compañía de Jesús por acceder al confesionario frente a la férrea defensa de la orden de los Predicadores, la sucesión de confesores, los ceses en el confesionario - especialmente evidentes en los reinados de Felipe III y Carlos II - nos traslucen una cuestión que ya los coetáneos advirtieron en más de una ocasión: el control de la conciencia del monarca representaba mucho más que el mero ejercicio del cumplimiento de un sacramento.

\begin{tabular}{|c|c|c|}
\hline \multicolumn{3}{|c|}{ CONFESORES REALES EN LA ESPAÑA DEL SIGLO XVII } \\
\hline REINADO & CONFESOR & CRONOLOGÍA \\
\hline \multirow{6}{*}{ Felipe III } & Antonio de Cáceres & $1592-1595$ \\
\hline & Pedro Fernández & $1595-1597$ \\
\hline & Gaspar de Córdoba & $1597-1604$ \\
\hline & Diego Mardones & $1605-1607$ \\
\hline & Jerónimo Xavierre & $1607-1608$ \\
\hline & Luis de Aliaga & $1608-1621$ \\
\hline \multirow{3}{*}{ Felipe IV } & Antonio Sotomayor & $1616-1643$ \\
\hline & Juan de Santo Tomás & $1643-1644$ \\
\hline & Juan Martínez & $1644-1665$ \\
\hline \multirow{11}{*}{ Carlos II } & Pedro Álvarez de Montenegro & $1668-1669$ \\
\hline & Tomás Carbonell & $1675-1676$ \\
\hline & Gabriel Ramírez de Arellano & $1676-1677$ \\
\hline & Pedro Álvarez de Montenegro & $1677-1678$ \\
\hline & Pedro de Montes & $1678-1679$ \\
\hline & Francisco Reluz & $1679-1680$ \\
\hline & Carlos de Bayona & $1680-1682$ \\
\hline & Tomás Carbonell & $1682-1686$ \\
\hline & Pedro Matilla & $1686-1698$ \\
\hline & Froilán Díaz & $1698-1700$ \\
\hline & Nicolás de Torres & $1700-1700$ \\
\hline
\end{tabular}

Fuente: Elaboración propia

Hasta un total de dieciocho confesores velaron por la conciencia de Felipe III, Felipe IV y Carlos II. No obstante, dejaremos a un lado, en esta ocasión, aspectos

II, Galería de personajes. Salamanca, Universidad Pontificia de Salamanca, 2004, pp. 399-246, revisión y actualización de un trabajo publicado en Diálogo ecuménico, 8, 1974, pp. 287-393; y TELLECHEA IDÍGORAS, J. I., "Religión y política. Diez cartas inéditas de fray Bernardo de Fresneda, confesor de Felipe II", en TELLECHEA IDÍGORAS, J. I.: El arzobispo Carranza. "Tiempos recios”, tomo II, Galería..., pp. 497-528. 
como la llegada o caída del confesionario, analizados en un trabajo anterior de forma detallada ${ }^{43}$, para centrarnos en un tema clave: ¿cuál fue la posición del confesor regio ante el gobierno de la Monarquía hispánica en el siglo XVII?

\section{a) Ausencia de funciones regladas}

El primer hecho que hemos de reseñar es que las funciones del confesor de los soberanos hispanos en el siglo XVII no se encontraban reguladas. Ninguna norma, ni etiqueta de la corte, ni en la capilla real, ni siquiera tras los cambios realizados en el reinado de Felipe IV estipularon el lugar que ocupaba el confesor real en relación a los integrantes de la capilla real ${ }^{44}$, lo que nos obliga a tener que intentar definir su posición y labor a través de fuentes indirectas principalmente.

Desde el siglo XVI la tratadística identificaba al confesor con el médico del alma, aspecto que no excluye a los confesores reales, pensamiento que perduró durante el siglo XVII en obras como la de Bellarmino ${ }^{45}$. La Monarquía hispánica no permaneció ajena a dichos ecos. Pedro de Maldonado, autor del Tratado del perfecto privado, dedicado al duque de Lerma, atendía a lo largo de todo un capítulo a la misión del confesor del privado, planteamiento que bien podría extrapolarse a los requisitos que se aspiraba tuviese todo confesor regio, recalcando aquellas cuestiones de las que éste debía alejarse:

...la primera que del oficio no haga autoridad, ni porque sea confesor del privado tengamos otro ídolo más que adorar, ni otro tribunal nuevo donde se den y se reciban memoriales y se despachen negocios; lo segundo, de tal manera sea confesor que no sea más que confesor; no sea procurador de los de su linaje, ni de su tierra; no de todas las obras pías, que el privado puede hacer, se ha de encargar, sino de

43 Véase nuestro trabajo "Médicos del alma...”, pp. 235-292.

44 En relación a las etiquetas en la corte española en la Edad Moderna, Archivo Ministerio Asuntos Exteriores. España. (AMAEE), Ms. 48, "Etiquetas de Palazio, Estilo y gobierno de la Casa Real que an de observar y guardar los criados de ella en el celo y exercicio de sus ofizios desde mayordomo maior y criados mayores hasta los demas criados inferiores"; Archive Ministère des Affaires Étrangères. France (AMAEF), Mémoires et documents, Espagne, article 10, "Etiquetas de la Real Cámara de S. M. C. el Señor Rey Dn. Phelipe IV”, fols. 5 ro-98 v ; BNE, Ms. 9887, “Etiqueta y ceremonial politico del palacio y corte del Rey de España”; ms. 9914, "Etiqueta o ceremonial de palacio y corte de España”; y ms. 10666, "Etiquetas generales de la Casa Real del Rey nuestro señor para el vso y exercicio de los oficios de sus criados; BOTTINEAU, Y.: “Aspects de la cour d'Espagne au XVIIe siècle: l'etiquette de la chambre du roi”, en Bulletin Hispanique, 1-2, 1972, pp. 138-157.

El único documento que hemos localizado de la época en el que se incluye al confesor del rey entre los miembros de la casa real no señala, sin embargo, cuáles eras sus funciones. AMAEF, Correspondance politique, Espagne, article 12, “Orden de la casa del rey" [1605], fols. 162 ro 187 ro, referencia en concreto, en fol. $167 \mathrm{r}^{\circ}$.

45 BELLARMIN, R: De officio principis christiani, Romae, Typographia B. Zannetti, 1619. 
las que pertenecen al descargo de su conciencia y alma, y si no está muy sobre sí, no habrá pretendiente que no le funde en caridad, piedad y en su oficio su pretensión, y que es tanta justicia que no sabe cómo, sin proveerle, puede absolver al privado. Tenga brío para decir al más pintado: señor, esto no es materia de confesión; y en otras: ni valgo ni puedo nada.

Lo tercero, no presuma tanto que piense que lo sabe todo, ni tenga celos de que el privado consulte o comunique con otros, antes, él le ha de aplicar a ello, holgándose de que acudan más y mejores médicos a trueque de que haya salud.

Lo cuarto, no se entrometa, por ser confesor, en cuanto hay en casa de un señor, que es presumptuosa temeridad querer que hacienda, criados y familia se gobierne todo por su mano. Lo que debe procurar es que para cosa de éstas haya ministros aptos, y lo que claramente viere que va injusto, avisarlo..."46.

La insistencia en que el confesor debía centrarse exclusivamente en las cuestiones de conciencia, pero distanciarse de otros "negocios" — donde se trasluce una clara alusión a los asuntos de Estado-, el hecho de incidir expresamente en que el confesor no debe ser un personaje omnipresente, obviamente no han de resultarnos indiferentes.

A inicios del siglo XVIII, el padre Manuel Pinegro, de la Compañía de Jesús, remitía a Luis XIV un escrito en el que representaba cuáles eran a su entender las obligaciones de los confesores regios de los monarcas españoles, y que exponía para que las conociera el padre Guillaume Daubenton, primer confesor de Felipe V. Pinegro hablaba de tres obligaciones: la atención a la proposición de beneficios concernientes a los consejos de Aragón, Italia y Flandes, la Inquisición y la atención a los asuntos eclesiásticos. ¿Nada más? El documento, conservado manuscrito en los fondos de los Archives du Ministère des Affaires Étrangères de París, va acompañado de otro documento, que por su tipología asemeja ser su minuta, encabezado con una elocuente frase: “...Depuis longtemps les confesseurs des Rois d'Espagne abusans de la foi blesse des princes, se sont ingresé dans le ministere politique d'une maniere qui les atendre sont odieux..." 47 .

Las labores de los confesores, por tanto, hasta la llegada de Daubenton — como, en realidad, lo seguirían siendo-, habían ido más allá de su intervención en la provisión de obispados y beneficios eclesiásticos o de su presencia en la Inquisición ${ }^{48}$.

46 MALDONADO, P.: Tratado del privado perfecto. Separata del Anuario Jurídico Escurialense, IV, 1963, pp. 795-796.

47 AMAEF, Correspondance politique, Espagne, article 90, fol. $385 \mathrm{r}^{\circ}$.

48 Un nuevo escrito del siglo XVIII, en este caso, de mediados de la centuria, redactado por Nicolás Gallo con motivo de su renuncia a ocupar el confesionario de Fernando VI, pretendía establecer notables diferencias entre las atribuciones de los custodios de la conciencia regia del Setecientos con sus predecesores, señalando que éstas consistían en: “...inspirar a V.M. los remedios mas oportunos con que debe proscrivir, y desterrar de su Reyno los vicios dominantes à la nacion; que à la verdad no son pocos los de la nuestra en la constitucion presente (...) una buena parte, y quizá la mas dificil de una Monarquia 


\section{b) Las intervenciones en asuntos eclesiásticos}

La misión principal del confesor en materia de Estado era la referente a la provisión de obispados, arzobispados, dignidades y beneficios eclesiásticos vacantes en todos los dominios de la Monarquía hispánica. Aunque la Cámara de Castilla era la institución encargada de atender a dicho tema ${ }^{49}$, el confesor ocupa un lugar clave. De hecho, era la persona que aconsejaba directamente al monarca sobre los individuos en los que debía recaer o no un determinado beneficio o dignidad eclesiástica, circunstancia que confería a dicho personaje, por tanto, enormes atribuciones, de las que los confesores franceses, por ejemplo, carecieron en vida de Richelieu, quien se reservó la autoridad para designar los beneficios vacantes.

Aunque lamentablemente tan sólo lo hemos localizado para un caso concreto, el de fray Luis de Aliaga, hemos podido estudiar las consultas realizadas a éste en 1610, conservadas en la sección Raros y Manuscritos, de la Biblioteca Nacional de España $^{50}$. Sin olvidar, por tanto, que nos encontramos ante un caso concreto y para un sólo año, así como que se trata de un instante en que Aliaga aún no vivía sus años de mayor poder en el cargo, sin embargo, de su lectura podemos extraer algunas conclusiones relativas a sus atribuciones en dicho oficio.

Una proporción significativa de las consultas conservadas en este volumen, comprendidas entre el 6 de febrero y 31 de diciembre de 1610, se encuentran relacionadas directamente con provisiones beneficios u obispados tras ser tratados por los consejos de turno - el de Estado, Portugal, Italia o Indias - y antes de ser ratificados los pertinentes nombramientos por el rey. En muchos casos, no obstante, ante todo

Catolica son las matterias eclesiasticas y la justa defensa de las regalias y privilegios, que por este lado miran a la Corona, y gravan los hombros de V. M. en cuya expedicion es preciso rozarse muchas vezes con la suprema caveza de la Yglesia, y con la Corte Romana (...)Añada V. M. a todo lo referido el cuidado de la elección de Pastores y Prelados de sus reynos (...) Pero aun se extiende oy a mas el cargo de confesor de V. M. pues como si fuera poco el peso de las obligaciones referidas se han recrecido insensiblemente à este oficio de algunos años à esta parte, otros muchos negocios, asi eclesiasticos, como politicos de que antiguamente estavan libres, y aun enteramente remotos los ministros que le exercian, corriendo su expedicion ò por la Camara, ò por los consejos respectivos, a quien tocava, segun la naturaleza de ellos. Pero oy, señor, se halla grabado, e implicado este empleo con casi todos los negocios mas arduos de la Monarquia...". Real Biblioteca. Madrid (RBM), Manuscrito II/2836, Papel sobre las circunstancias que deben concurrir en la Persona que exerza el delicado encargo de Confesor del Rey escrito el año de 1770, fols. $62 \mathrm{r}^{\mathrm{o}}-63 \mathrm{v}^{\mathrm{o}}$. Existe otra copia de este documento en AMAEF, Memoires et documents, Espagne, article 4, "Papel sobre las circunstancias que deven concurrir en quien tubiese el delicado cargo de confesor de Rey y los motivos que en esta representacion expuso a la Magestad de Fernando VI el Padre Dn. Nicolas Gallo", fols. $118 \mathrm{r}^{\mathrm{o}}-133 \mathrm{v}^{\mathrm{o}}$.

49 DELGADO BARRADO, J. M.: "La Cámara de Castilla: fuentes legislativas para un estudio institucional”, en Hispania, 180, 1992, pp. 59-81.

50 BNE, Ms. 1923. Papeles del padre confessor Fr. Luis de Aliaga tocantes a diuersos negocios de que se le ha pedido parecer. Del año de 1610. 
para Portugal, Indias e Italia, el confesor se limita a aceptar las ternas remitidas desde los consejos, sin condicionar, así, al menos vía escrita, la resolución del monarca.

Es cierto que no podemos hablar de que su neutralidad al respecto fuera total, puesto que en algún caso sí intervino decisivamente para aconsejar a Felipe III, con la intención de influir en su decisión. En el año 1610 localizamos dos respuestas en este sentido. Una, la consulta del consejo de Italia en relación a la provisión del arzobispado de Macera, en la que el confesor interviene directamente, recomendando, en primer lugar, al monarca que designase a un español, y posteriormente señalando el nombre de fray Juan de Ezpila, confesor del conde de Benavente, por considerarlo el más digno para el cargo, arguyendo que poseía experiencia en materias de Estado, bien es cierto que considerando también factible la opción de otro de los candidatos presentados por el Consejo: Juan Ruíz de Camargo ${ }^{51}$; y otra, la consulta del consejo de Portugal sobre la provisión de una canonjía en la iglesia mayor de Évora, para la que el confesor no dudó en señalar de modo preciso a su penitente quién debía ocuparla: Francisco Noguera, que servía como confesor del rey en Lisboa ${ }^{52}$.

No debió de ser muy diferente la labor de sus sucesores en este sentido. La proximidad al monarca era tal que fray Antonio de Sotomayor ${ }^{53}$, confesor de Felipe IV, incluso cuando teóricamente había dejado su puesto - aunque mantenía el título- en 1643, recomendaba al soberano se concediese la plaza vacante del obispado de Teruel a un inquisidor, el abad de Huerta ${ }^{54}$.

51 Ibídem, fols. $56 \mathrm{r}^{\mathrm{o}}-57 \mathrm{r}^{\mathrm{o}}$.

52 Ibídem, fol. $471 \mathrm{r}^{\circ}$.

53 Natural de Valencia do Miño, en Portugal, donde nació en 31 de agosto de 1557, era hijo de Baltasar de Sequeiros Benavides y Sotomayor, natural de Santo Tomé de Freigeiro, donde disfrutaba de un mayorazgo, y de Isabel de Ozores Sotomayor, natural de La Guarda (Portugal). Era descendiente de Pedro Álvarez de Sotomayor, conde de Camiña. Destacado miembro de la orden de Predicadores, en 1612 actuó como definidor en el Capítulo General de su orden, celebrado en Roma. En 1616 se produjo su llegada a la corte, atendiendo, según un manuscrito de la época, primero el confesionario del duque de Lerma, dando desde ahí el salto al círculo real, con el nombramiento por Felipe III como confesor de los infantes, y de manera especial del príncipe heredero, actividad que continuó desempeñando tras el ascenso al trono de éste, ya como confesor del rey. También actuó como confesor de la reina Isabel de Borbón. Desde su llegada a la corte se sucedieron sus atribuciones en diversas instituciones: consejero de la Inquisición entre 1622 y 1632, consejero de Estado, y comisario general de la Santa Cruzada, desde 1631, entre otros. En 2 de septiembre de 1632 fue nombrado inquisidor general, título que ostentó hasta noviembe de 1643. En 1643 dejó de ejercer como confesor del rey, aunque mantuvo el titulo, así como su estrecha relación con el monarca, como es posible advertir a través de la correspondencia cruzada entre ambos. Sotomayor otorgó testamento en Madrid, el 1 de septiembre de 1646. Falleció, en dicha ciudad, dos años después, en 3 de septiembre de 1648, a los noventa y un años. Una semblanza del personaje en LÓPEZ ARANDIA, Ma A.: "Médicos del alma...".

54 Antonio de Sotomayor a Felipe IV, en Madrid, [sin día] de noviembre de 1643. Recogido por ESPINOSA RODRÍGUEZ, J.: Fray Antonio de Sotomayor y su correspondencia con Felipe IV, Vigo, s. e., 1944, carta XXXVIII. 
Pero las provisiones de obispados, dignidades o beneficios no constituyeron las únicas cuestiones remitidas al confesor en materia religiosa. De hecho, poseemos ejemplos de la intervención del confesor, caso de fray Gaspar de Córdoba, en la presentación de las ternas entre las que se debía elegir al general de la orden mercedaria, por ejemplo ${ }^{55}$; o volviendo de nuevo a las consultas realizadas a fray Luis de Aliaga observamos cómo el confesor intervino en conflictos internos de las diócesis, caso de los problemas acaecidos en la de Córdoba; o en materias relativas a fundaciones religiosas, como la consulta remitida sobre la licencia que se había solicitado para establecer un seminario de estudiantes ingleses en Madrid.

Tampoco podemos obviar su actuación como garante de los principios morales que debían imperar en la Monarquía, atribuciones que en principio también recaían en la cámara de Castilla. La opinión del confesor tuvo un gran peso ante problemas como la conveniencia o no de la prohibición de las comedias teatrales, por ejemplo, en tiempos de Felipe III, contra las que fray Gaspar de Córdoba no dudó en alzar su voz al considerarlas un foco de pecados tan depravados y reprobables para la Corona como el parricidio o el adulterio ${ }^{56}$.

En relación a las órdenes religiosas, el confesor no sólo intervino directamente en las cuestiones relacionadas de manera directa con la fundación de establecimientos religiosos, sino también en temas vinculados a la reforma de las órdenes, una labor en la que fray Juan de Santo Tomás tuvo una destacada intervención como miembro de una junta creada al efecto, en la que se intentaron afrontar lo que se consideraban eran algunos problemas que afectaban a la vida cotidiana de estas congregaciones, y que se entendía contraria al cumplimiento de la observancia y los votos de pobreza y obediencia, vía que para Filippini constituye un intento por buscar una mayor intervención de la propia Corona en los nombramientos internos de cada orden ${ }^{57}$.

\section{c) El confesor y la Inquisición}

La presencia y actuación de los confesores en la Inquisición, una de las principales instituciones de la Monarquía hispánica en el siglo XVII continúa ofreciendo numerosos interrogantes, aún cuando el confesor del rey fue notable protagonista en ella ${ }^{58}$.

55 A.S.V. Arch. Nunz. Madrid, 55, fols. 221 r-222 v, Nuncio Ginnasio al cardenal Pedro Aldobrandini, en relación a los tres candidatos que el confesor del rey consideraba merecedores del generalato mercedario: Alonso de Monroy, Pedro Machado y Diego Coronel, en Valladolid, 8 de junio de 1602; y Arch. Nunz. Madrid, 55, fol. 237 r, Nuncio Ginnasio al cardenal Pedro Aldobrandini, sobre la elección del general, en Valladolid, 15 de junio de 1602.

56 BNE, Ms. 10748, fols. $1 \mathrm{r}^{\mathrm{o}}-3 \mathrm{r}^{\mathrm{o}}$.

57 FILIPPINI, O.: FILIPPINI, O., “”De poca sustancia”?. Juan de santo Tomás, O.P., confessore di Filippo IV di Spagna, e un tentativo di riforma della vita religiosa (1643-1644). Parlare di riforma per alludere ad altro", en Archivum Fratrum Praedicatorum (en prensa).

58 Véase, como síntesis, MARTÍNEZ MILLÁN, J.: La Inquisición española, Madrid, Alianza Editorial, 2007, especialmente, pp. 121-130. 
La estructura del consejo de la Inquisición, sometido a notables cambios entre finales del siglo XVI e inicios del XVII, contó con la directa oposición del confesor fray Gaspar de Córdoba, siendo ésta una de las causas de su cese.

Pero sin duda, el posicionamiento de estos religiosos, como hermanos de la orden de Santo Domingo, se vio especialmente reforzada por la consecución, por parte de fray Luis de Aliaga, en 1614, del privilegio de contar con una plaza fija en dicho Consejo para un miembro de la orden ${ }^{59}$.

Así, varios confesores durante la centuria contaron con plaza en el consejo de la Inquisición, pero lo que es más relevante, dos de ellos, fray Luis de Aliaga y fray Antonio de Sotomayor, llegaron a presidir la institución compatibilizando ambos cargos, el primero entre 1619 y 1621, al final de su etapa como confesor, por tanto; y el segundo entre $1632^{60}$ y 1643 , cuando fue relevado ${ }^{61}$.

La ostentación de dicho puesto les permitía dirigir las actuaciones de este organismo, que por entonces extendía su jurisdicción también a las Indias Occidentales, Sicilia y Cerdeña ${ }^{62}$. El hecho, no obstante, de que tan sólo dos de los dieciocho confesores regios de la centuria alcanzasen la presidencia inquisitorial, ha llevado a Poutrin a reseñar que no se puede considerar esta circunstancia como una tendencia habitual ${ }^{63}$.

Desconocemos, sin embargo, cuál fue realmente el influjo de su etapa al frente del cargo, recibido entre la orden dominica y la ciudad de Zaragoza, para el caso de Aliaga, con enorme regocijo, como lo denotan los festejos que tuvieron lugar con tal motivo en Valladolid ${ }^{64}$ o en la ciudad natal del confesor ${ }^{65}$; y que, para Sotomayor sig-

59 Sobre estas circunstancias, MARTÍNEZ MILLÁN, J.: "Cambios en la corte", en MARTÍNEZ MILlÁN, J. y VISCEGLIA, Ma . A. (Dirs.): La monarquía de Felipe III: La Corte, Madrid, Fundación Mapfre, vol. III., pp. 261-269.

60 AHN, Consejos, Patronato de Castilla, legajo 15224, exp. 35.

61 En relación a su cese en la Inquisición puede resultar interesante la carta remitida al efecto por Sotomayor a Felipe IV, en Madrid, 14 de julio de 1643. Reproducida por ESPINOSA RODRÍGUEZ, J.: Fray Antonio.... A pesar de ello, de la lectura de su correspondencia se desprende que aún en 23 de julio de 1643 mantenía su plaza. También a partir de esta correspondencia conocemos que Felipe IV le permitió mantener los gajes que obtenía en dicha institución. Al respecto, ibidem, carta en Madrid, 7 de noviembre de 1743 , carta XL.

62 DEDIEU, J.-P.: L'administration de la foi. L'Inquisition de Tolède (XVIe-XVIIe siècles), Madrid, Casa de Velázquez, 1989.

63 POUTRIN, I.: "Le confesseur royal en Espagne sous Philippe III", en Revue d'Histoire Moderne et Contemporaine, 53-3, 2006, p. 16.

64 RBM, Manuscrito II/2134, doc. 55, Diego de Santana a Diego de Sarmiento, Valladolid, 30 de enero de 1619.

65 BNE, R/ 4908. Compendio de las fiestas que ha celebrado la imperial ciudad de Çaragoça. Por auer promouido la Magestad Catholica del Rey nuestro Señor, Filipo Tercero de Castilla, y Segundo de Aragon: al Illustrissimo señor don Fray Luis Aliaga, su confessor, y de su Real Consejo de Estado, en el oficio y cargo supremo de Inquisidor General de España. Zaragoza, Juan de Lanaja y Quartanet, impresor, 1619. 
nificó una oportunidad excepcional para la consolidación de su red familiar en diversos oficios de dicha institución ${ }^{66}$. Un período, por otro lado, en el que las relaciones con Roma vivieron años especialmente difíciles, ante todo, durante el pontificado de Urbano VIII (1623-1644), etapa en la que se publicó el índice de libros prohibidos de 1640, coincidiendo con el gobierno de Sotomayor, y en cuya realización participó también el futuro confesor fray Juan de Santo Tomás; en la que las necesidades de los frentes bélicos en Cataluña supusieron la promulgación de una real cédula en la que se obligaba a todos los oficiales de la Inquisición, al igual que a los caballeros de órdenes militares, a servir en el ejército ${ }^{67}$; y en la que a la caída de Olivares, en sus últimas semanas como inquisidor, fray Antonio de Sotomayor luchó contra los intentos por limitar las funciones del inquisidor general ${ }^{68}$.

Aunque Aliaga y Sotomayor fueron los confesores reales que mayor poder alcanzaron en la institución inquisitorial al presidirla, varios de los dominicos que atendieron la conciencia de los monarcas hispanos en el siglo XVII disfrutaron de diversos oficios en ella ${ }^{69}$ : fray Juan Martínez del Corral, confesor de Felipe IV, fue nombrado calificador de la Inquisición en $1636^{70}$; mientras que entre los confesores de Carlos II, fray Tomás Carbonell actuó como consultor coincidiendo con su primera etapa al frente del confesionario, entre 1675 y $1676^{71}$; fray Pedro Álvarez de Mon-

66 CONTRERAS, J.: El Santo Oficio de la Inquisición de Galicia, Madrid, Akal, 1982.

67 BNE, V.E./50/80. Concesión de fray Antonio de Sotomayor, en relación al despacho de la real cédula.

68 GARCÍA CÁRCEL, R., MORENO MARTÍNEZ, D.: Inquisición. Historia Crítica, Madrid, Temas de Hoy, 2000, p. 107.

69 AHN, Catálogo de las causas contra la fe seguidas ante el Tribunal del Santo Oficio de la Inquisición de Toledo y de las informaciones genealógicas de los pretendientes a oficios del mismo, Madrid, Tip. Revista Archivos, Bibliotecas y Museos, 1903; AHN, Consejo de la Suprema Inquisición. Catálogo de las informaciones genealógicas de los pretendientes a cargos del Santo Oficio, Valladolid, Imp. Casa Social Católica, 1928.

70 Natural del Corral de Almoguer, ingresó en su orden religiosa en el convento de Santa Cruz de Segovia. Nombrado confesor del príncipe Baltasar Carlos en 20 de febrero de 1643, así como de su hermana María Teresa, fue nombrado confesor de Felipe IV al fallecer fray Juan de Santo Tomás en 1644, actuando como tal hasta la muerte del monarca. No obstante, no era la primera ocasión en que su nombre aparecía como candidato a ocupar el confesionario real, puesto que con motivo del cese de fray Antonio Sotomayor se planteó la posibilidad de que él fuera su sustituto. Actuó también como confesor de la reina doña Isabel de Borbón, e incluso con el tiempo, de la reina Mariana de Austria, antes de la llegada de Nithard. Para una semblanza más detallada, véase LÓPEZ ARANDIA, Ma . A.: "Médicos...".

71 Natural de Madrid, hijo de Ginés Carbonell, pintor, natural de Albacete, y María Sánchez, natural de Fonseca, nació el 6 de enero de 1621. No era un desconocido en la corte, puesto que fue capellán y desde el 1 de julio de 1672 ostentó el cargo de predicador real. También fue confesor de don Fernando de Valenzuela, quien, para Jaime Contreras, fue el promotor de su nombramiento y el causante de su destitución a favor de Ramírez de Arellano. Rigió en dos ocasiones el confesionario de Carlos II. La primera, desde el 16 de noviembre de 1675, sustituyendo a fray Pedro Álvarez de Montenegro hasta el 29 de agosto de 1676, cuando fue alejado de la corte, siendo designado obispo de Plasencia, aunque terminó renunciando a dicho nombramiento. Fue de nuevo llamado al confesionario regio en 1 de abril de 1682, 
tenegro fue designado familiar del Santo Oficio de Valladolid en 1677, año en que regresaría al confesionario del monarca después de un período apartado de él ${ }^{72}$; fray Pedro de Montes, confesor entre 1678 y 1679, y uno de los personajes más desconocidos, compatibilizó sus labores al lado del rey con una plaza en el consejo de la Inquisición ${ }^{73}$; al igual que sucedió con sus sucesores fray Francisco Reluz ${ }^{74}$, fray Pedro Matilla, acusado por sus detractores de ambicionar el puesto de inquisidor general ${ }^{75}$; y fray Froilán Díaz ${ }^{76}$, quien terminó, como Aliaga en su día ${ }^{77}$, siendo sometido a un proceso inquisitorial, que tuvo mucho más de un conflicto personal entre el inquisidor general don Baltasar de Mendoza y Sandoval (1699-1705) y el antiguo confesor, que de un proceso justificado ${ }^{78}$.

actividad que desempeñó hasta 1686, manteniendo el título de obispo de Sigüenza, tras obtener la oportuna licencia papal para no tener que ejercer la residencia. Allí regresó el 17 de diciembre después de ser cesado por segunda vez. Falleció el 5 de abril de 1692. Para una semblanza, véase LÓPEZ ARANDIA, Ma. A.: "Médicos...".

72 AHN, Consejo de la Suprema Inquisición. Catálogo..., p. 23.

73 Confesor real entre el 24 de junio de 1678, sucediendo a fray Pedro Álvarez de Montenegro, y el 10 de mayo de 1679, cuando falleció en el convento de Nuestra Señora del Rosario, de Madrid, donde residía, "entre diez y onze de la noche". LÓPEZ ARANDIA, Ma. A.: "Médicos...".

74 Natural de Pozorrubio, en el obispado de Cuenca, era hijo de Bartolomé Sánchez y María Reluz. Era pariente del también dominico y obispo de Oviedo, Tomás Reluz. Actuó como confesor de Carlos II entre el 13 de junio de 1679 y el 30 de julio de 1680, etapa en la que ocupó también una plaza como inquisidor. Ya las crónicas del convento de Salamanca ligan directamente su ascenso a dicho cargo a su proximidad a don Juan José de Austria. Apartado del confesionario, coincidiendo con la caída del duque de Alba y el ascenso del duque de Medinaceli al frente del gobierno, continuó residiendo en el convento del Rosario de Madrid, manteniendo su plaza como inquisidor, de la que no fue desposeído. Falleció en 31 de mayo de 1686 -para algunos autores, 1688-. LÓPEZ ARANDIA, Ma . A.: "Médicos...".

75 Natural de Toro. Con anterioridad a ser designado confesor regio ostentó el cargo de definidor de su orden religiosa en 1686 para acudir al capítulo general celebrado en Roma dicho año, actividad que desempeñaba cuando fue nombrado confesor de Carlos II el 24 de diciembre de dicho año, sucediendo a fray Carlos Bayona. Bien recibido en el cargo, con el tiempo, fue centro de numerosas críticas por su actuación en la Inquisición, donde ingresó en 1687, y en el consejo de Estado. Las presiones abocaron a su caída a finales de marzo de 1698. Pocos días después de ser cesado, falleció, en 1 de abril, en el convento madrileño de Nuestra Señora del Rosario, donde recibió sepultura. Véase, LÓPEZ ARANDIA, Ma . A.: "El sacrílego...", y LÓPEZ ARANDIA, Ma. A.: "Médicos...".

76 Catedrático de prima de la Universidad de Alcalá, fue confesor de Carlos II entre el 6 de marzo de 1698 y 1700. Su nombramiento fue promovido por Luis Fernández Portocarrero. Fue acusado de participar en los hechizos al rey que tuvieron lugar desde 1698, lo que motivó su cese tanto de dicho Consejo como de su oficio de confesor regio. Se inició entonces un largo proceso inquisitorial lleno de irregularidades. No fue hasta 1704 cuando después de la intervención directa del maestro general dominico, del nuncio e incluso del nuevo monarca Felipe V, se diera por finalizado el proceso, absolviéndolo de todos los cargos y restituyéndolo en su plaza de consejero de la Inquisición. LÓPEZ ARANDIA, Ma . A.: "Médicos...".

77 Tras ser cesado de su cargo, coincidiendo con la muerte de Felipe III en 1621, se abrió un proceso inquisitorial contra el confesor, bajo la acusación de haber realizado proposiciones sospechosas de luteranismo, causa que quedó, sin embargo, en suspenso, después de su fallecimiento en 1626. GARCÍA CÁRCEL, R., MORENO MARTÍNEZ, D.: Inquisición ...., p. 75.

78 Entre las numerosas copias manuscritas sobre el proceso, BNE, Ms. 5724, 10473 y 10474 . Igualmente interesantes las informaciones recogidas en ASV, Arch. Nunz. Madrid, especialmente, 46 (legajo de- 


\section{d) Más allá de asuntos espirituales}

A pesar de que aún queda mucho por descubrir, no podemos considerar un mero tópico la afirmación de las amplias atribuciones que recaían sobre el confesor, aún cuando, como hemos advertido, no existía una regulación de sus funciones. Así, el confesor regio será un personaje omnipresente a lo largo de la centuria en las distintas instituciones de la administración de la Monarquía hispánica ${ }^{79}$.

En realidad, no podemos considerar ésta una cuestión novedosa. Ya desde el reinado de Carlos V, pero ante todo en el de Felipe II, los confesores regios comienzan a intervenir directamente en el consejo de Estado - recordemos el nombramiento como consejero de García de Loaysa - pero incluso en cuestiones tan alejadas, a priori, de los asuntos de conciencia, como la hacienda, como advertimos en el caso de fray Diego de Chaves o fray Bernardo de Fresneda.

No obstante, sí podemos afirmar cómo a lo largo de esta centuria la presencia del confesor se generaliza, incluso, a pesar de la presencia de los validos, en un momento, por otra parte clave, cuando los consejos coexisten con una multitud de juntas.

Aunque no exista una norma, observamos cómo junto al despacho de la concesión del título de confesor real, normalmente se entrega el despacho para la entrada de éste a la junta de Obras y Bosques, institución de origen impreciso — para unos autores, nacida en 1545, para otros no lo hace hasta 1570 - , encargada de todo lo relativo a la casa del rey y de los reales $\operatorname{sitios}^{80}$. La participación de los confesores en ella co-

dicado íntegramente a dicho asunto, con documentación entre 1701 y 1705), y además, 51, 52, 53, 56, 58 y Segretaria di Stato, Spagna, 189. Algunos estudios al respecto en CUETO RUÍZ, R.: Los hechizos de Carlos y el proceso de Fr. Froilán Díaz, confesor real, Madrid, La Ballesta, 1966; GARCÍA CÁRCEL, R. (Coord.): Historia de España. Siglos XVI y XVII. La España de los Austrias, Madrid, Cátedra, 2003, pp. 424-425; TUERO BERTRAND, F.: Carlos II y el proceso de los hechizos, Gijón, Fundación Alvar González, 1998.

79 En esta línea, resulta interesante el reciente trabajo de NEGREDO DEL CERRO, F.: "Gobernar en la sombra. Fray Antonio de Sotomayor confesor de Felipe IV. Apuntes políticos", en Entre el cielo y la tierra. Las elites eclesiásticas en la Europa Moderna. Revista Universitaria Mágina, 13, 2009, pp. 85-102.

80 Para una definición de las funciones de dicho organismo, pueden resultar interesantes las palabras de Gil González Dávila: “...ejerce jurisdicción privativa sin dependencia de otros Consejos en las cosas de Gobierno: Justicia, Gracia y Hacienda; para la conservación y aumento de las casas, alcázares y bosques reales que están a su cargo...”. La Junta ejercía justicia, civil y criminal “...de los que sirven, si delinquen en sus cargos, y contra los que contravienen a las provisiones y cédulas que se dan para la conservación y aumento de la caza, pesca, hierba y leña de los bosques (...) También da premios, consultando al Rey personas para los oficios de las Casas y Bosques Reales y capellanías de ellos... ". Atendía también a cuestiones propias de la hacienda, despachaba títulos como los de cazador, montero y marcador mayor. GONZÁLEZ DÁVILA, G.: Teatro de las Grandezas de la villa de Madrid, Corte de los Reyes Católicos de España, Madrid, Imp. Tomás Iunti, 1623, pp. 521-522. Para una visión más completa sobre las atribuciones de este organismo, BALTAR RODRÍGUEZ, J. F.: Las Juntas de Gobierno en la Monarquía Hispánica (Siglos XVI-XVII), Madrid, Centros de Estudios Políticos y Constitucionales, 1998, pp. 464485; DÍAZ GONZÁLEZ, F. J.: La Real Junta de Obras y Bosques en la época de los Austrias, Madrid, Dykinson, 2002, pp. 407-443; y SÁNCHEZ, D. M.: Las Juntas Ordinarias. Tribunales permanentes en la corte de los Austrias, Madrid, UNED, 1995. 
menzó a resultar especialmente activa a partir de 1605, cuando la junta se "refunda", y ante todo, desde 1606, cuando ésta deja de depender del consejo de Hacienda ${ }^{81}$.

Especialmente relevante fue la participación de fray Luis de Aliaga en esta institución en lo que podríamos considerar su "segundo período" al frente del confesionario, tras la ruptura y su aparente reconciliación con el duque de Lerma, en la segunda década del siglo XVI. En 1615, Felipe III, tras el fallecimiento del presidente del consejo de Castilla, Juan de Acuña, marqués del Valle, ordenó que las sesiones fueran presididas por su confesor, y que éstas tuviesen lugar en su celda ${ }^{82}$.

Después de la muerte de Aliaga, sus sucesores en el cargo continuaron formando parte de dicha junta. No obstante, en un período de inestabilidad como el reinado de Carlos II, el hecho de que en realidad no existiera una norma escrita que fijara la obligación de que el confesor participase en esta institución fue aprovechada para intentar evitar que fray Pedro de Montes fuese admitido como miembro nato de ésta ${ }^{83}$.

Pero la junta de Obras y Bosques no fue la única de la que formó parte el confesor. A lo largo de esta centuria es posible localizar a diversos confesores en la junta de Estado, encargada de atender a las consultas del consejo de Estado, convocada normalmente ante cuestiones concretas, que en tiempos de Felipe IV llegó a celebrarse en distintas ocasiones en la propia celda de fray Antonio de Sotomayor; la junta de Vestir la Casa, encargada de las vestimentas de todos los individuos con oficio y ocupación en el palacio real, desaparecida en 1668 cuando se incorporó al consejo de Hacienda; la junta da Facenda o junta para la Hacienda de Portugal, creada en 20 de octubre de 1601, que terminó siendo absorbida por la junta de Desempeño, en la que participó, desde su fundación, fray Gaspar de Córdoba; la junta de la Media Anata, creada en 1631, para entender el cobro de dicho tributo fijado sobre los oficios, cargos y mercedes otorgadas por el monarca - con excepción de los eclesiásticos-, y cuyas sesiones en sus orígenes se celebraron, al igual que las de la junta de Estado, en la celda de fray Antonio de Sotomayor; y obviamente en juntas con un claro trasfon-

81 DÍAZ GONZÁLEZ, F. J.: La Real..., p. 136. Para Garma y Durán, el confesor debía intenvenir en esta institución “...por el descargo de las reales conciencias en la satisfacción a los labradores de los daños de la caza y demás puntos semejantes que pueden ocurrir...”. GARMA Y DURÁN, F. J.: Theatro universal de España, Madrid, 1751, vol. IV, p. 517. Citado también por DÍAZ GONZALEZ, F. J.: La Real..., p. 376. Para los avatares de la junta de Desempeño, resulta fundamental, CARLOS MORALES, C. J. de: "Junta de Desempeño General (1602-1607)", en MARTÍNEZ MILLÁN, J. y VISCEGLIA, Ma. A. (Dirs.): La monarquía..., vol. III, pp. 767-792.

82 AGPM, Administrativa, legajo 853, carta del duque de Lerma a Tomás de Angulo, en Madrid, 13 de enero de 1616.

83 AGPM, Personal, expediente personal, caja 701, exp. 26, carta de Jerónimo de Eguía a don Bernardino de Aranda, en Palacio [Madrid], 21 de junio de 1678. 
do religioso, caso de la junta de Teólogos o la junta magna de Teólogos, esta última instituida con motivo de la visita del príncipe de Gales a Madrid en $1623^{84}$.

El confesor del monarca no sólo estuvo presente en las innumerables juntas que atendieron las más diversas cuestiones que afectaban a la vida de la Monarquía a lo largo del siglo XVII. Los consejos también contaron con su presencia, ante todo el de Estado, considerado por Escudero el consejo supremo de la Monarquía ${ }^{85}$, heredero del consejo Real, instituido en 1526, y junto al de Guerra, los dos únicos presididos por el propio rey, órgano encargado de atender a los asuntos concernientes a la política exterior, y por lo tanto, de enorme trascendencia en un período, por otra parte, tan conflictivo como el siglo XVII.

Esta presencia no constituye, tampoco, una novedad, puesto que se remonta al siglo XVI, cuando encontramos los primeros atisbos en el reinado de Carlos V, con la participación de García de Loaysa en el consejo de Estado, y con posterioridad, en el de Felipe II, cuando localizamos a fray Diego de Chaves en dicha institución entre 1578 y 1592. Así, durante el reinado de Felipe III, advertimos la actuación de varios confesores en esta institución: fray Gaspar de Córdoba contó con una plaza de consejero desde 1604; fray Jerónimo Xavierre lo hizo entre 1606 y 1608; mientras que fray Luis de Aliaga no consiguió el acceso como consejero de pleno derecho hasta 1615, aunque con anterioridad acudiría de forma ocasional a sus sesiones, especialmente cuando se trataban asuntos relativos a las relaciones con Roma ${ }^{86}$. Aún resulta necesario, sin embargo, atender con detalle a las consultas de dicho Consejo, para conocer con exactitud cuál fue su grado de participación, y sobre todo hasta qué punto la opinión de los confesores resultó decisiva o simplemente se trató de una presencia simbólica.

No menos interesante, aunque todavía más desconocida que la anterior, debe resultarnos la presencia de algunos de estos individuos, como fray Gaspar de Córdoba, en tiempos de Felipe III, y fray Antonio de Sotomayor, con Felipe IV, en el consejo de Guerra, en unos años muy significativos para la Monarquía, con el problema de los Países Bajos candente durante el primer reinado, y sobre todo, en el segundo reinado, en medio de una agresiva política exterior dirigida por el conde-duque de

84 Al respecto, BALTAR RODRÍGUEZ, J. F.: Las Juntas....; y SÁNCHEZ, D. M.: Las Juntas.....

85 ESCUDERO, J. A.: "Consultas al Consejo de Estado: trámites irregulares en el reinado de Carlos II", en ESCUDERO, J. A.: Administración y Estado en la España Moderna, Valladolid, Junta de Castilla y León, 2002, p. 109. Sobre esta institución, BARRIOS, F.: El Consejo de Estado de la Monarquía absoluta, 1521-1812, Madrid, Consejo de Estado, 1984.

86 POUTRIN, I.: “Le confesseur...., p. 15. 
Olivares, con numerosos frentes abiertos en Italia, las Provincias Unidas, Francia, la guerra de los Treinta Años, etc ${ }^{87}$.

Y fundamental, la intervención del confesor en la cuestión hacendística. Es cierto, no obstante, que el confesor del rey no fue el único religioso, ni el único custodio de la conciencia de un personaje tan influyente que se incumbió en dicha materia, si recordamos la acción del padre Hernando Salazar, confesor del conde-duque de Olivares en relación a este tema, cuestión que ha sido analizada por Negredo del Cerro ${ }^{88}$.

La mayor parte de las referencias que hemos localizado sobre este aspecto para el siglo XVII nos abocan a la misma conclusión. La cuestión hacendística se entiende como un asunto de especial dedicación para el confesor, al encontrarse directamente vinculada con el bienestar de los súbditos, y por tanto, por convertirse en una misión fundamental para el monarca, puesto que de su mala gestión podría derivarse su condenación eterna. No podemos comprobar, sin embargo, a tenor de las fuentes consultadas hasta el momento, la hipótesis planteada por De Carlos Morales identificando la participación de confesores como Fresneda, Chaves y Córdoba en el Consejo y juntas relativas a la hacienda con “...las expectativas de los intereses de su facción y sus deudos..." "89.

Destacada intervención en esta materia tuvo fray Gaspar de Córdoba, confesor de Felipe III entre 1597 y $1604^{90}$, especialmente a través de juntas como la de Dos, de Tres, de Cuatro, la junta de Hacienda de Portugal, y sobre todo, desde 1603, de la junta de Desempeño General, muchas de cuyas reuniones, incluso, se celebraron en su propia celda ${ }^{91}$.

87 Para el primero, AMAEF, Correspondance politique, Espagne, article 12, fol. 144 ro. Sobre el posicionamiento de fray Juan de Santo Tomás, véase FILIPPINI, O.: “"Semper pauperibus, praencipus militibus". Aspetti della direzione della coscienza regale e dell'operato di un confessore regio durante le campagne militari. Juan de santo Tomás, O. P. e Filippo IV in Aragona nel 1643 en el 1644", en Congreso de historia militar. Guerra y sociedad en la monarquía hispánica. Política, estrategia y cultura en la Europa moderna (1500-1700), Madrid, Consejo Superior de Investigaciones Científicas, 2006.

88 NEGREDO DEL CERRO, F.: "La hacienda y la conciencia: las propuestas del confesor del Conde Duque para el saneamiento de las finanzas reales", en Cuadernos de Historia Moderna, 27, 2002, pp. 171-196. También en este caso, algunos de los confesores del siglo XVI, como fray García de Loaysa, con Carlos V, y sobre todo a fray Bernardo de Fresneda y fray Diego de Chaves, con Felipe II, ya habían participado activamente en estas cuestiones, al formar parte del consejo de Hacienda. Véase en relación a esto, CARLOS MORALES, C. J. de: El Consejo de Hacienda de Castilla, 1523-1602: Patronazgo y clientelismo en el gobierno de las finanzas reales durante el siglo XVI, Valladolid, Junta de Castilla y León, 1996, sobre todo para los reinados de Carlos V y Felipe II, pp. 35, 93, 127-158, 191.

89 Ibídem, p. 191.

90 A su implicación en estos asuntos, y sobre todo, a su posición contraria a la política dictada desde el entorno del monarca se atribuyó directamente su caída, como se señalaba en algunos textos de la época. Al respecto, AMAEF, Correspondance politique, Espagne, article 12, "Vida del rey de España y de los privados, $1609^{\prime \prime}$, fols. $131 \mathrm{r}^{\circ}-150 \mathrm{r}^{\circ}$.

91 Algunas notas al respecto en FEROS, A.: Kingship and Favoritism in the Spain of Philip III, 1598-1621, Cambridge, Cambridge University Press, 2000, pp. 128-129 y 158-163. Una posterior edición en castellano de dicha obra en FEROS, A.: El duque de Lerma: realeza y privanza en la España de Felipe III, Madrid, Marcial Pons, 2002. 
La crítica situación económica ya preocupaba de manera notable en 1599, cuando la junta, presidida por el propio confesor, decidió solicitar al rey moderación “...ponga orden y mucha...”- en los gastos de la casa real, señalándole que dicha medida sería ejemplar para sus súbditos, al mismo tiempo que reconocía que constituiría una notable ayuda para la real hacienda. La presencia del confesor en asuntos relativos a la hacienda fue tal, que en 1601 se llegaba a considerar que cualquier otro cargo sobre la materia, antes con gran significación, caso del contador mayor, o incluso cualquier plaza en el consejo de Hacienda, se encontraba devaluado, puesto que era el dominico quien centralizaba cualquier acción al respecto.

Fray Gaspar de Córdoba participará también en la junta del Desempeño General, creada en mayo de 1603 con plena jurisdicción sobre materias relativas a la administración y distribución de la hacienda real, que implicaba atender a la gestión de todos los "recursos variables" (impuestos de millones, tres gracias, así como cualquier arbitrio), de la que también formaron parte don Pedro Franqueza ${ }^{92}$ y el presidente del consejo de Castilla ${ }^{93}$.

$\mathrm{Su}$ sucesor, fray Diego Mardones adquirió, del mismo modo, un gran protagonismo en el seno de la junta de Hacienda ${ }^{94}$. De hecho, Mardones se convirtió en receptor de numerosos escritos que veían en él no sólo a un miembro más de esta junta, sino a alguien con gran influencia sobre el monarca y por ende, con capacidad suficiente para poder lograr un giro en las líneas directrices de la política financiera de la Monarquía. Muy significativo en este sentido resulta un discurso remitido a Mardones, con la petición expresa de que se lo presentara al rey, referente a la pretensión de imponer una tasa sobre el pan, y en el cual se criticaba duramente al soberano por dicha acción que se estimaba oprimía de manera directa a sus súbditos: “...No merece nombre de Padre ni de Amo el que no tiene cuidado de que sus hijos y criados tengan el pan necesario..." 95 .

92 Sobre la actuación de este personaje, véase, GARCÍA GARCÍA, B.: "Pedro Franqueza, secretario de sí mismo. Proceso a una privanza y primera crisis del valimiento de Lerma (1607-1609)", en Annali di Storia Moderna e Contemporanea, 5, 1999, pp. 21-42.

93 Luis Cabrera de Córdoba, en 1 de noviembre de 1603 volvía a insistir en que el confesor y Ramírez de Prado, “...llevan en peso todas las materias de Hacienda... ”. CABRERA DE CÓRDOBA, L.: Relaciones de las cosas sucedidas, principalmente en la Corte, desde el año 1599 hasta el de 1614, Madrid, s. e., 1857, p. 193.

94 Ibídem, p. 262.

95 BNE, Ms. 11160, carta a fray Diego de Mardones, en Zafra, 27 de julio de 1605, fols. 15 ro -16 $\mathrm{v}^{\mathrm{o}}$ (el fragmento citado en el fol. $15 \mathrm{v}^{\mathrm{o}}$ ). Un ataque similar al monarca, lamentándose de la situación, en otra carta remitida al confesor señalaba que “...La primera obligacion de los reyes como de los pastores es hacer fuerte y sano y engordar el ganado para usar de el, pero andar de mula coja, y cada vez mas coja y flaca!...". Ibídem, carta a fray Diego de Mardones, sin fecha, fol. 17 ro . 
Ésta no fue la única carta recibida por el dominico presionándole para que intercediese ante Felipe III en contra de los gravámenes a los que se estaba sometiendo a la población, encomendándole “...adbierta V. P. R. siempre por amor de Dios a que las cargas publicas se repartan generalmente, y con igualdad a todos... " 96 .

Su posición en contra de lo que consideraba innecesarios gastos del Estado, le llevó a enfrentarse directamente con el duque de Lerma, quien, por otra parte, con anterioridad había sido su penitente, acusándolo de despilfarro, actitud que llegó a denunciar ante el rey, con el pronóstico de que se condenaría si no remediaba dicha situación ${ }^{97}$. El duro enfrentamiento con el monarca y con el valido, en noviembre de 1606, del que se tienen noticias a partir de los despachos del nuncio, conservados en el fondo Borghese del Archivo Secreto Vaticano, acabó con el cese del confesor, que fue alejado de la corte nombrándolo obispo de Córdoba:

Il confessore di Sua Maesta disse al re, ch'è impegnato tutto quello, che ha, et che non puo essere in stato peggiore di quello, in che si troua Sua Maesta. Lo disse al duca, il quale parlo co'l confessore, dicendoli, che non sapeua perche causa haueua detto quello à Sua Maesta. Il confessore gli rispose che non sapeua con che ragione l'hauesse potuto dire il contrario, et che gli disse molti altri particolari, nelli quali il duca si resenti assai, et inuiorno il confessore a Madrid, doue si à malo, et hora e ricascato con pericolo, et dice, che non uol seruir piu, et ch'è una gran cosa, che il mondo habbia ad essere gouernato dal duca di Lerma, et ho per facil cosa, che lo mutino dandoli qualche vescouato...98.

Apenas tres dias después, el nuncio volvía a insistir en la cuestión:

...Ho inteso adesso da persona, che il sa dal confessore del Re, ch'egli disse a Sua Maesta che la sua azienda è tutta consumata, et che la Maesta sua apra gli occhi, perche è gabbata, et gli fanno sottoscriuere cose preiudiciali, et poco conuenienti, et che se no rimedia andera all'inferno, et l'istesso dise al duca di Lerma, co'l quale gridò assai, et poi il duca se n'andò dalla contessa di Lemos piangendo, et dicendoli che no(n) uoleua andare all'inferno, et che si uoleua ritirar a fare uita monastica...99.

96 Ibídem, carta a fray Diego de Mardones, sin fecha, fol. $17 \mathrm{r}^{\mathrm{o}}-\mathrm{v}^{\mathrm{o}}$. Otra petición similar, quejándose sobre la subida de la moneda de plata y el impuesto de los dieciocho millones, en ibídem, carta a fray Diego de Mardones, en Zafra, 27 de octubre de 1696, fols. $22 \mathrm{r}^{\mathrm{o}}-26 \mathrm{v}^{\mathrm{o}}$.

97 PÉREZ BUSTAMANTE, C.: “La España de Felipe III”, en Historia de España de Menéndez Pidal, tomo XXIV, Madrid, Espasa-Calpe, 1983, p. 142.

98 Despacho del nuncio, en Madrid, 20 de noviembre de 1606. ASV, Borghese, II, 272, fol. 64 r.

99 Despacho del nuncio, en Madrid, 23 de noviembre de 1606. Ibídem, fol. 67 r-v. El episodio es recogido también en GARCÍA Y GARCÍA, B. J.: La Pax Hispanica. Política exterior del Duque de Lerma. Leuven, Leuven University Press, 1996, pp. 370-371. 
No menos relevante fue la injerencia en temas económicos de los confesores de Felipe IV. En este sentido, resulta relevante atender a un documento redactado por fray Juan de Santo Tomás, confesor entre 1643 y 1644, por encargo de Felipe IV, titulado El modo de discurrir acerca de peccados de Reyes, conservado en los fondos del Archivo Secreto Vaticano ${ }^{100}$, posteriormente editado como Breve tratado y muy importante que por mandado de Su Magestad escrivió el reverendísimo P. fray Juan de santo Toma para saber hazer una confesión general, al ser incluido en otra obra de Santo Tomás, Catecismo o verdadera explicación de la doctrina christiana. El texto representa un verdadero posicionamiento del confesor sobre la forma de gobernar, y en el que las recomendaciones al monarca en materia hacendística están muy presentes a lo largo de todo el escrito ${ }^{101}$.

En este contexto, no podemos olvidar que fray Juan de Santo Tomás, meses antes de ser nombrado confesor, había sido llamado a la corte para participar en una junta creada en febrero de 1643 para analizar la posible legitimidad del monarca en la recaudación de impuestos entre el clero, ante las dificultades financieras de la Coro$\mathrm{na}^{102}$, y en la que coincidió con el entonces confesor real, fray Antonio de Sotomayor.

Fray Juan de Santo Tomás retomaba, por tanto, una vez consolidada su posición en el confesionario, un tema que preocupaba especialmente al monarca. ¿Hasta qué punto las consideraciones del confesor vendrían motivadas por el hecho de que la propuesta del rey para la que se había creado la junta de 1643 no había sido aprobada?

Aunque desconocemos la respuesta, lo cierto es que es imposible obviar cómo la preocupación por la situación económica y por su repercusión en la sociedad está presente en toda la obra, siendo numerosos los consejos que al respecto se ofrecen al soberano.

De hecho, resulta curioso cómo al hablar del modo de gobernar para no incurrir en el primer pecado que se consideraba todo rey podía cometer: aquel contrario a la Iglesia, se criticaba abiertamente la venta de hábitos de órdenes militares, pero sobre todo, se recomendaba a Felipe IV que no se exigieran tributos a la Iglesia, salvo como último recurso: “...Que no se pida prestado, o venda a las iglesias la plata que les

100 ASV, Spagna, Appendice (1701-1805), I, doc. 13.

101 Sobre la labor de este personaje, véase FILIPPINI, O.: "La disciplina dell'autorità: autorevolezza del confessore e legitima del potere regale secondo Juan de Santo Tomás O. P., confessore di Filippo IV di Spagna (1643-1644)", en Rivista di Filosofia Neoscolastica, 4, 2002, pp. 587-635; FILIPPINI, O.: La coscienza del re. Juan de santo Tomás, O. P.: confessore di Filippo IV di Spagna (1643-1644), Firenze, Leo S. Olschki Editore, 2006.

102 Dos visiones al respecto en DOMÍNGUEZ ORTIZ, A.: Politica y hacienda de Felipe IV, Madrid, Pegaso, 1983, pp. 182-184; FILIPPINI, O.: La coscienza del rey..., pp. 91-114. 
sobra, sino después de apurada toda la plata de los seculares, porque en las iglesias haze horror el tocar, sino a lo último..." "103.

El confesor criticaba los gastos innecesarios causados con motivo de enfrentamientos bélicos, citando expresamente las campañas en Cataluña, señalando era necesario evitar gastos que consideraba superfluos ${ }^{104}$. Del mismo modo, estimaba fundamental la reducción de gastos en consejos y juntas, también superfluos a su entender medidas que en su opinión debían comenzar por la reducción en el número de los integrantes de los primeros, comenzando por las plazas supernumerarias, y por la supresión de las segundas.

Pero ante todo, fray Juan de Santo Tomás señalaba que la conciencia del monarca estaba obligada a proteger a sus súbditos. Así, no dudaba en criticar la decisión tomada en consejo de aprobar la baja de la moneda, cuestionaba abiertamente las obras del palacio del Buen Retiro, por considerarlas habían ocasionado un gasto desmedido e innecesario en un momento crítico como el que se atravesaba ${ }^{105}$; llamaba de modo especial la atención al soberano sobre la presión fiscal a la que se estaba sometiendo a la población, advirtiéndole que en caso de no estar éstos realmente justificados podría haber pecado, bien por acción o por omisión ${ }^{106}$.

A pesar de las duras y directas críticas al gobierno de su penitente, el confesor no fue cesado de su cargo. No obstante, su repentino fallecimiento tan sólo le permitió mantenerse en su puesto un año.

103 DESDEVISES DU DEZERT, G.: "Du moyen de discourir sur les Péché des Rois. Par Fray Juan de Santo Thomas, confesseur de Philippe IV (1643). (Texte inédit espagnol du XVIIe siècle)", en Mélanges littéraires publiées à l'occasion du centenaire de la Faculté des Lettres de Clermont-Ferrand, Imp. G. Mont-Louis, s.a., pp. 37-54.

104 “...gastando en armas y en galas lo que no era necesario...”. Ibídem.

105 “...La obra del Retiro ha sido donde mucho se ha reparado por el gasto, por parecer desusado y superfluo, quando estamos publicando estrema necesidad. Se debe mirar si está por hazer alguna satisfacción de lo gastado alli si alguna cosa se ha perdido, o tomado para su adorno y está por satisfacer, y lo mismo se debe mirar en qualquier otra cosa que se aya pedido, o tomado qualquier gasto, y no se ha satisfecho, para que se ajuste y se procure satisfacer... ”. Ibídem. En realidad, el confesor no sólo atacó la construcción del nuevo palacio por considerarlo un gasto superfluo, sino que amplió sus críticas a los gastos ocasionados por otros entretenimientos reales en fiestas, fuegos y monterías.

106 “...En la multitud de cargos y tributos que ha havido y la bexación que se haze en cobrar por los ministros, claman los pobres al zielo, y ha sido mucho lo que ha padecido y padece este pueblo, la culpa que en esto puede cargar al príncipe es por dos causas: el primero si dio occasión a las guerras, para cuyo socorro es menester pedir tan inmensos tributos; el segundo la omisión de no castigar los ministros que hazen las bexaciones en las cobranzas, y poner forma que sea vista y conveniente. Lo mismo es en los donativos que se han pedido con tanta violencia y exacción que los que les han dado los más son involuntarios y a pura fuerza los dan.

El haver levantado la moneda y las demás mudanzas que en ello ha havido, siendo el útil sólo para el Rey, y el daño para el pueblo, se mire quanto carga la consciencia del principe, por ser materia tan grave... "Ibídem. 
No parece tampoco, a tenor del desarrollo del reinado, que las advertencias de fray Juan tuvieran especial eco en la forma de gobernar de Felipe IV. Ante una hacienda esquilmada por los cuantiosos gastos que la Corona debía afrontar, en 1646 y 1653 se intentó retomar por las Cortes un proyecto planteado por vez primera a finales del gobierno de Felipe II, que conllevaría la imposición de un gravamen de cuatro reales en cada fanega de trigo que se llevara a moler. Un nuevo impuesto que sin embargo, implicaría, según se planteaba, la supresión de otros como las alcabalas, las sisas y millones ${ }^{107}$.

Entre las voces contrarias a la medida, de nuevo se alzó la de otro confesor real, fray Juan Martínez del Corral, quien en sus Discursos theologicos y polyticos ${ }^{108}$, erigiéndose en portavoz de los súbditos más necesitados, clamó por la supresión de dicho proyecto, arguyendo que éstos consumían más pan que aquellos más acomodados y por tanto, serían los que más perjudicados resultarían de su imposición. Aunque aún habría que determinar en qué medida la opinión del confesor influyó, lo cierto es que la implantación de dicho impuesto terminó siendo desestimada ${ }^{109}$.

\section{A modo de epílogo}

El confesor del rey se erige en una Monarquía confesional, como la hispánica, en una figura omnipresente. Esta circunstancia deriva, en gran medida, de la propia misión que dicho individuo tenía encomendada y que fue reiterada insistentemente por los tratadistas de la época: la dualidad en el alma del príncipe (como hombre y como soberano, persona privada y pública), por la que su confesor debe velar.

La orden de Predicadores, cuya influencia en la Monarquía hispánica y su especial vinculación a la dinastía de los Austrias, aún latía con fuerza, fue la encargada de atender la conciencia de los soberanos hispanos durante todo el siglo XVII, en lo que se nos presenta como un reducto de la orden religiosa frente al imparable ascenso de la Compañía de Jesús en buena parte de los confesionarios reales del resto de Europa.

107 Para dichos acontecimientos, GELABERT, J. E.: Castilla convulsa (1631-1652), Madrid, Marcial Pons, 2001.

108 La obra, compuesta por un total de diez discursos, centraba lo que podríamos considerar una primera parte, es decir, los cuatro primeros discursos a asuntos ligados directamente con temas eclesiásticos, tratando cuestiones como la residencia o el traslado de los obispos de sus diócesis; mientras que a partir del quinto y hasta el octavo, se centra en asuntos fiscales; pasando a tratar algunas cuestiones sobre las órdenes militares en los dos últimos. Un estudio de la obra, atendiendo de manera especial a los aspectos económicos, en DOMÍNGUEZ ORTIZ, A.: "Un testimonio sobre la vida rural en el siglo XVII", en DOMÍNGUEZ ORTIZ, A.: Estudios de Historia económica y social, Granada, Universidad de Granada, 1987, pp. 211-221.

109 DOMÍNGUEZ ORTIZ, A.: "Iglesia y Estado..., p. 265. 
No existen, sin embargo, a efectos prácticos, grandes diferencias entre ellas en el intento por que la atención al monarca trascendiera de los límites exclusivamente espirituales. Así, los confesores regios hispanos adquirieron notables atribuciones en el plano político, formando parte de distintas instituciones del gobierno de la Monarquía, y a pesar de proyectos como el propuesto por Juan de Ribera a inicios de la centuria, no quedaron sometidos a ningún órgano que controlara sus actuaciones. La activa participación de los confesores en los consejos y juntas de la Monarquía les permitió intervenir en cuestiones que fueron más allá de las provisiones de obispados o beneficios eclesiásticos, actuando en asuntos vinculados directamente con la política interior y exterior de la Monarquía de los Austrias, labor de la que hemos pretendido ofrecer una primera aproximación. 